\title{
Creation of a Neonatal Thrombosis Center and its Use to Successfully Treat Infants with Severe Thromboses
}

\author{
Shailly Gaur ${ }^{1}$, Matthew Saxonhouse ${ }^{2}$ and Ashley Hinson ${ }^{3 *}$ \\ ${ }^{1}$ Department of Pediatrics, Levine Children's Atrium Health, USA \\ ${ }^{2}$ Department of Pediatrics, Division of Neonatology, Levine Children's Atrium Health, USA \\ ${ }^{3}$ Department of Pediatrics, Division of Hematology Oncology, Levine Children's Atrium Health, USA
}

*Corresponding author: Ashley Hinson MD, Department of Pediatrics, Division of Hematology Oncology, Levine Children's Atrium Health, 1001 Blythe Blvd, MCP Suite 601, Charlotte, NC, USA.
Received Date: January 07, 2021

Published Date: January 21, 2021

\begin{abstract}
Background: Clinically significant thrombosis, which can be life threatening, is a common problem in the neonatal period, affecting up to 6.8 per 1,000 neonatal intensive care admissions. These infants have increased risk for bleeding complications from anticoagulant therapy due to immature coagulation systems, concomitant infections, inflammation and coagulopathies, and CNS hemorrhage risk due to prematurity. Thus, care for these infants requires a specialized multidisciplinary team, composed of neonatologists and hematologists, along with pharmacy support.
\end{abstract}

Objectives: We aim to describe the development of a neonatal thrombosis center at our institution, co-run by a neonatologist with expertise in neonatal hematology, and a pediatric hematologist. The utility of the center will be explored through the case review of four neonates with large, life threatening thromboses, successfully treated with systemic tissue plasminogen activator (TPA). We will also describe the development of a neonatal thrombosis database for studying risk factors and treatments for neonatal thrombosis.

Methods: Protocols for evaluation and treatment of neonatal thromboses were prepared, based on literature review and best practices, and presented and approved by the institution's pharmacy and therapeutics committee. Anticoagulation protocols including heparin, low molecular weight heparin, and systemic TPA were created electronically within our computerized order entry system. A protocol for consulting the neonatal thrombosis team was created and presented during grand rounds. All neonates with thromboses are followed by the neonatal thrombosis team as outpatients, with thrombophilia evaluations completed as necessary. Information regarding age, risk factors, diagnoses, treatments and outcomes are then compiled in a neonatal thrombosis database.

Results: Four infants with life-threatening thromboses were successfully treated with systemic TPA using our neonatal thrombosis treatment center. These include a full-term infant with an occlusive thrombus in the main pulmonary artery, a full term infant with a mural thrombus in the heart, a full term infant with an occlusive thrombus in the aortic arch, and a 26-week premature infant with a large right atrial thrombus.

Conclusion: Neonates, especially those in intensive care, are at increased risk for thromboses, which can be life-threatening. Treatment of neonates with significant thromboses requires a multidisciplinary approach. Creation of a neonatal-thrombosis team and treatment center can be used to effectively treat these patients and gather data about their care and outcomes. To our knowledge, this is one of the first dedicated neonatal thrombosis teams.

Keywords: Neonatal thrombosis; Thromboses; Systemic TPA; Neonatal center

Abbreviations: CNS: central nervous system; TPA: tissue plasminogen activator

\section{Introduction}

Clinically significant thromboses, which can be life-threatening, are a common problem in the neonatal period, affecting up to 6.8 per 1,000 neonatal intensive care admissions. The presence of venous access devices, sepsis, maternal factors, dehydration, and 
prematurity contribute to the development of these thromboses [1]. These infants have increased risk for bleeding, complications from anticoagulant therapy due to immature coagulation systems, concomitant infections, inflammation and coagulopathies, and CNS hemorrhage risk due to prematurity [2]. Thus, care for these infants requires a specialized multidisciplinary team, composed of neonatologists and hematologists, along with pharmacy support. We describe the development of a neonatal thrombosis center, co-run by a neonatologist with expertise in neonatal thrombosis, and a pediatric hematologist. The center focuses on care of neonatal thrombosis through education, treatment, and data collection. Initially, protocols for evaluation and treatment of neonatal thromboses were prepared, based on literature review and best practices, and presented and approved by the institutional pharmacy and therapeutics committee. In order to streamline care across providers, anticoagulation protocols including heparin, low molecular weight heparin, and systemic TPA (tissue plasminogen activator) were created electronically within our computerized order entry system. A protocol for consultation of and between the thrombosis center neonatologist and hematologist was prepared and presented to the department of pediatrics (Figure 1) [3]. This includes follow up of all neonates with clinically significant thromboses post hospital discharge in the outpatient thrombosis clinic, with thrombophilia evaluations completed as necessary. The neonatal thrombosis database collects information such as demographics, diagnostic, treatment and outcome information on neonates treated at our institution with thromboses. Finally, from an education standpoint, our collaborative treatment center physicians conducted a grand rounds presentation on neonatal thromboses and co-published a chapter on neonatal thrombosis diagnosis and management.

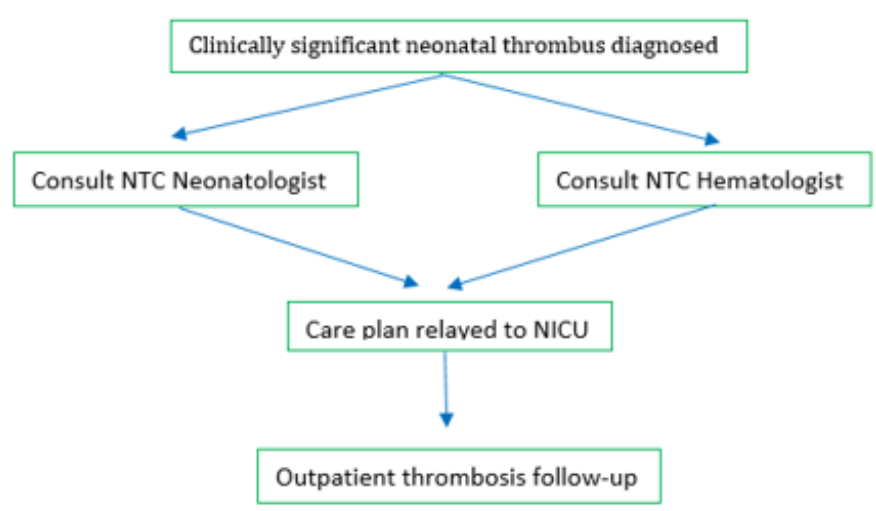

Figure 1: Algorithm for Consultation of Neonatal Thrombosis Center Providers.

\begin{tabular}{|c|c|c|c|}
\hline \multicolumn{4}{|c|}{$\begin{array}{l}\text { Dose titrations should be as follows: } \\
0.03 \mathrm{mg} / \mathrm{kg} / \mathrm{hr} \rightarrow 0.06 \mathrm{mg} / \mathrm{kg} / \mathrm{hr} \rightarrow 0.1 \mathrm{mg} / \mathrm{kg} / \mathrm{hr} \rightarrow 0.3 \mathrm{mg} / \mathrm{kg} / \mathrm{hr} \\
\text { Max dose }=0.3 \mathrm{mg} / \mathrm{kg} / \mathrm{hr} !\end{array}$} \\
\hline Lab/Imaging & Goal & Factor Replacement & TPA Titration \\
\hline Fibrinogen q6h & $100-200 \mathrm{mg} / \mathrm{dL}$ & $\begin{array}{l}\text { If }<100 \mathrm{mg} / \mathrm{dL} \text {, give } \\
\text { cryoprecipitate. If } \\
\text { persistently } \\
<100 \mathrm{mg} / \mathrm{dL} \text {, decrease } \\
\text { TPA by } 25 \%\end{array}$ & $\begin{array}{l}\text { If }>200 \mathrm{mg} / \mathrm{dL} \text {, increase } \\
\text { TPA as above }\end{array}$ \\
\hline D dimer $q 6 h$ & Elevated & $\mathrm{n} / \mathrm{a}$ & $\begin{array}{l}\text { If low, increase TPA as } \\
\text { above }\end{array}$ \\
\hline Platelets & $>100,000 \times 10^{\wedge} 3 / \mathrm{uL}$ & $\begin{array}{l}\text { Give platelets for } \\
<100,000 \times 10^{\wedge} 3 / \mathrm{uL}\end{array}$ & \\
\hline $\begin{array}{l}\text { Ultrasound } \\
\text { Q8h arterial; } \\
\text { Q24h venous }\end{array}$ & $>95 \%$ clot lysis & n/a & $\begin{array}{l}\text { If }<50 \% \text { lysis, increase } \\
\text { TPA as above. } 51-94 \% \\
\text { lysis, continue same TPA } \\
\text { dose. If }>95 \% \text { lysis, stop } \\
\text { TPA. }\end{array}$ \\
\hline
\end{tabular}

Figure 2: Systemic TPA Titration Guidelines.

\section{Case Presentations}

Four infants with life-threatening thromboses were successfully treated with systemic TPA using our neonatal thrombosis treatment center. TPA was initiated and titrated based off best practices (figure 2). Infant 1 was a 37/1 gestational age infant who presented at 11 days of life with several days of poor feeding and weight gain, along with fever and watery diarrhea. There was no significant thrombophilia family history. Imaging by echocardiogram revealed 
a thrombus in the main pulmonary artery, and therapeutic heparin was initiated. Follow up imaging after one day revealed clot propagation, so he was transitioned to systemic TPA for 72 hours, with improvement in thrombus, followed by a therapeutic course of low molecular weight heparin in outpatient follow up. Infant 2 was a 38/4 gestational age infant with late prenatal care and GBS+ mother. He presented at 10 days of life with hypothermia, hypoglycemia, and respiratory failure. An echocardiogram revealed a mural cardiac thrombus, and he was immediately started on systemic TPA, with clinical and radiographic improvement. He then completed a treatment course of low molecular weight heparin, followed by aspirin prophylaxis. Infant 3 was a 26 week gestational age infant, with a pregnancy complicated by advanced maternal age, gestational hypertension, and maternal history of multiple miscarriages but no known thrombophilias. The infant presented at day of life 17 with acute respiratory failure and coagulase negative staphylococcal sepsis. Ultrasound imaging revealed a significant mobile thrombus in the right atrium. Systemic TPA was given, followed by low molecular weight heparin for 6 weeks, with complete resolution. Finally, infant 4 was $38 / 6$ gestational age infant, whose prenatal course was complicated by teenage pregnancy, limited/late prenatal care, opiate, tobacco and marijuana use, and GBS positivity in the mother. This infant presented on the first day of life with a cardiac murmur and decreased lower extremity pulses. An echocardiogram demonstrated an occlusive thrombus in the aortic arch. Systemic TPA was immediately started, followed by heparin and lower molecular weight heparin, and finally aspirin. All of these infants are doing well and thriving (Table 1).

Table 1: Case Reports: Use of Systemic TPA in High Risk Neonatal Thromboses.

\begin{tabular}{|c|c|c|c|c|c|c|}
\hline $\begin{array}{l}\text { Infant } \\
\text { ID }\end{array}$ & $\begin{array}{c}\text { Gestational } \\
\text { Age (Weeks) }\end{array}$ & Maternal Factors & Pregnancy Complications & $\begin{array}{c}\text { Age at Thrombus } \\
\text { Diagnosis }\end{array}$ & $\begin{array}{l}\text { Location of } \\
\text { Thrombus }\end{array}$ & Presenting Symptoms \\
\hline Infant 1 & $37 / 1$ & Teenage pregnancy & Pre-eclampsia & 11 days & $\begin{array}{l}\text { Main pulmo- } \\
\text { nary artery }\end{array}$ & $\begin{array}{l}\text { Poor feeding/weight } \\
\text { gain, watery diarrhea }\end{array}$ \\
\hline Infant 2 & $38 / 4$ & Late prenatal care & GBS+ & 10 days & Mural cardiac & $\begin{array}{l}\text { Hypothermia, hypo- } \\
\text { glycemia, respiratory } \\
\text { failure }\end{array}$ \\
\hline Infant 3 & 26 & $\begin{array}{c}\text { Advanced maternal age, } \\
\text { history of multiple miscar- } \\
\text { riages }\end{array}$ & Pregnancy-induced Hypertension & 17 days & Right atrium & Acute respiratory failure \\
\hline Infant 4 & $38 / 6$ & $\begin{array}{l}\text { Teenage pregnancy, late/ } \\
\text { limited prenatal care }\end{array}$ & $\begin{array}{l}\text { GBS+ untreated, History of opiate, } \\
\text { tobacco, marijuana use, small for } \\
\text { gestational age }\end{array}$ & 1 day & Aortic Arch & $\begin{array}{l}\text { Decreased lower } \\
\text { extremity pulses, heart } \\
\text { murmur }\end{array}$ \\
\hline
\end{tabular}

\begin{tabular}{|c|c|c|c|c|}
\hline Infant ID & Family History & Catheter Presence & Relevant Infections & Anticoagulation \\
\hline Infant 1 & Non-contributory & $\begin{array}{l}\text { None prior to thrombus forma- } \\
\text { tion }\end{array}$ & No identified infection & $\begin{array}{l}\text { Initially heparin. Transitioned to TPA after in- } \\
\text { creased clot burden. Then lovenox. }\end{array}$ \\
\hline Infant 2 & Non-contributory & $\begin{array}{l}\text { None prior to thrombus forma- } \\
\text { tion }\end{array}$ & None & $\begin{array}{c}\text { TPA, then } 6 \text { months of lovenox, then aspirin } \\
\text { prophylaxis }\end{array}$ \\
\hline Infant 3 & $\begin{array}{l}\text { Maternal grandfather with deep } \\
\text { venous thrombosis }\end{array}$ & PICC in Superior Vena Cava & $\begin{array}{l}\text { Coagulase-negative } \\
\text { Staphylococcus }\end{array}$ & TPA then lovenox for 3 months \\
\hline Infant 4 & $\begin{array}{l}\text { Maternal great grandmother with } \\
\text { stroke; paternal grandmother } \\
\text { with thrombi, paternal aunt with } \\
\text { deep venous thrombosis, mater- } \\
\text { nal family with history of multiple } \\
\text { miscarriages }\end{array}$ & $\begin{array}{l}\text { None prior to thrombus forma- } \\
\text { tion }\end{array}$ & None & TPA, then lovenox, then aspirin prophylaxis \\
\hline
\end{tabular}

\section{Discussion}

Through these varied cases, it is apparent that early recognition of thromboses and the need for anti-coagulation is imperative for positive outcomes. Many of these patients presented to area hospitals and clinics prior to being transferred to our center, in order to utilize the Neonatal Thrombosis Center via consultation with both hematology and neonatology. Access to a tertiary care center with expertise in the diagnosis and treatment of complicated neonatal thrombosis, is necessary for prompt and safe anticoagulation. Through use of the center, coordinated follow-up is made easier, continuing to contribute to favorable outcomes, as risk assessments for future thromboses for the infants (or future infants in the case of identified thrombophilias) are completed and outpatient anticoagulation is followed closely through thrombus resolution. As more outlying centers have become aware of the program, phone consultations have also increased, providing resources to areas with poor access to subspecialty care. This unique group of patients often present with non-specific signs and symptoms, as evidenced in our cases. Two of the four had no apparent risk factors or history to suggest a clot as the underlying cause. Thus, high suspicion for a cardiovascular or thromboembolic cause for symptoms in these neonates helps lead to diagnosis and timely treatment. 
Another consideration for the treatment of these patients via our dedicated neonatal thrombosis center is the creation of standardized treatment protocols, accessible throughout our health system, which has allowed for rapid and safe initiation of systemic TPA and improved outcomes of these very high-risk neonates. Given the discrepancies in access to care and the limited availability to subspecialists at all locations, these step-by-step algorithms are a valuable resource to all providers faced with emergent presentations, in order to act effectively and quickly to provide the appropriate care [4-7].

\section{Conclusion}

In conclusion, neonates, especially those in intensive care, are at increased risk for thromboses, which can be life-threatening. Treatment of neonates with significant thromboses requires a multidisciplinary approach. Creation of a neonatal-thrombosis team and treatment center can be used to effectively treat these patients and gather data about their care and outcomes. To our knowledge, this is one of the first dedicated neonatal thrombosis teams.

\section{Acknowledgement}

None.

\section{Conflict of Interest}

No conflict of interest.

\section{References}

1. Revathi Rajagopal, Fook-Choe Cheah, Paul Monagle (2016) Thromboembolism and Anticoagulation Management in the Preterm Infant. Seminars in Fetal \& Neonatal Medicine 21(1): 50-56.

2. Janet Malowany, David Knoppert, Anthony Chan, Dion Pepelassis, David Lee (2007) Enoxaparin Use in the Neonatal Intensive Care Unit: Experience Over 8 Years. Pharmacotherapy 27(9): 1263-1271.

3. Marilyn J Manco-Johnson (2006) How I Treat Venous Thrombosis in Children. Blood 107(1): 21-29.

4. Paul Monagle, Anthony KC Chan, Neil A Goldenberg, Rebecca N Ichord, Janna M Journeycake, et al. (2012) Antithrombotic Therapy in Neonates and children: Antithrombotic Therapy and Prevention of Thrombosis, 9th ed: American College of Chest Physicians Evidence-Based Clinical Practice Guidelines. Chest 141(2 Supp): e737S-e801S.

5. Jennifer Armstrong-Wells (2013) Neonatal Thrombosis. In: Pedro A deAlarcon EJW, Robret D Christensen, editor. Neonatal Hematology. Second edn, Cambridge University Press, new York, USA, pp. 277-285.

6. M Wang, T Hays, V Balasa, Bagatell R, Gruppo R, et al. (2003) Lowdose Tissue Plasminogen Activator Thrombolysis in Children. J Pediatr Hematol Oncol 25(5): 379-386.

7. AD Michelson, E Bovill, P Monagle, M Andrew (1998) Antithrombotic Therapy in Children. Chest 114(5 Supp): 748S-769S. 